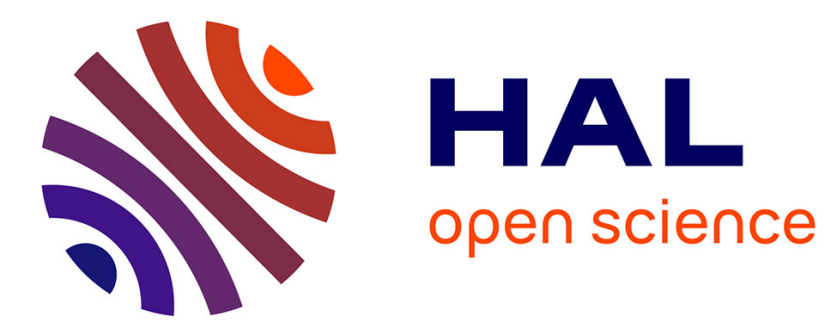

\title{
Assessment of the Performance of Long-Range-Corrected Density Functionals for Calculating the Absorption Spectra of Silver Clusters
}

Franck Rabilloud

\section{- To cite this version:}

Franck Rabilloud. Assessment of the Performance of Long-Range-Corrected Density Functionals for Calculating the Absorption Spectra of Silver Clusters. Journal of Physical Chemistry A, 2013, 117 (20), pp.4267-4278. 10.1021/jp3124154 . hal-03030676

\section{HAL Id: hal-03030676 https://hal.science/hal-03030676}

Submitted on 30 Nov 2020

HAL is a multi-disciplinary open access archive for the deposit and dissemination of scientific research documents, whether they are published or not. The documents may come from teaching and research institutions in France or abroad, or from public or private research centers.
L'archive ouverte pluridisciplinaire HAL, est destinée au dépôt et à la diffusion de documents scientifiques de niveau recherche, publiés ou non, émanant des établissements d'enseignement et de recherche français ou étrangers, des laboratoires publics ou privés. 


\section{Assessment of the performance of long-range corrected density functionals for calculating the absorption spectra of silver clusters}

Franck Rabilloud*

Institut Lumière Matière, UMR5306 Université Lyon 1 - CNRS, Université de Lyon 69622 Villeurbanne Cedex, France

E-mail: franck.rabilloud@univ-lyon1.fr

${ }^{*}$ To whom correspondence should be addressed 


\begin{abstract}
We assess the accuracy of several long-range corrected (LC-) density functionals for the prediction of absorption spectra of silver clusters by time-dependent density functional theory. Several types of LC-functionals, with the exact Hartree-Fock exchange at long range, are used: those applying the long-range correction to a standard GGA-type functional (LC-BP86, LC- $\omega$ PBE) or to a local meta-GGA functional (LC-M06L), and two global hybrid functionals (CAM-B3LYP and $\omega$ B97x). The spectra calculated with those density functionals are in good agreement with the recent accurate experimental measurements. We show that CAM-B3LYP and $\omega \mathrm{B} 97 \mathrm{x}$ are ones of the most accurate functionals for evaluating the electronic excitation energies, while LC-M06L is more effective in reducing the occurrence of spurious states. The long-range correction appears to be essential in describing the absorption spectra of large clusters. The description of the plasmon-like band with LC-functionals, as transitions associated to excitations from $s$ orbitals to $s+p$ orbitals, is in fairly good agreement with the classical interpretation as a collective excitation of valence $s$-electrons.
\end{abstract}

Keywords : TDDFT, long-range corrected functionals, absorption spectra, silver clusters, noble metal clusters

\title{
Introduction
}

In a few years, the Time-Dependent Density Functional Theory (TD-DFT) has become one of the major theoretical approaches for calculating the absorption spectra of molecular systems. The developments in the last decade in both methods and algorithms, and also the increase of capacities of computers, now allow the theoretician to reproduce and interpret experimental spectra and to predict spectra of complex systems containing hundreds of electrons within a fully quantum treatment. For valence-excited states, the typical error lies within the range of $0.1-0.5 \mathrm{eV}$, which is comparable with the error of high-level post-Hartree-Fock methods like MRCI, EOM-CCSD or CASPT2. However, these correlated approaches are much more computer intensive, and consequently can be used only for small-sized systems, while TD-DFT represents a good compromise 
between accuracy and computational effort for the calculation of excited states of medium-sized and large-sized systems. The formal foundations of TD-DFT comprise the Runge-Gross theorem, ${ }^{1,2}$ the time-dependent Kohn-Sham equations, ${ }^{3}$ and then the derivation of the TD-DFT equations in the linear response formulation by Casida. ${ }^{4}$ The resolution of the equations gives some properties of the excited states like excitation energies, oscillator strengths, geometries, etc. However, several approximations are employed in the derivation of the equations. Most calculations are still restricted to the adiabatic linear-response formulation of TD-DFT which is not able to describe states with substantial multi excitation character, despite some recent developments to go beyond the conventional approximations. ${ }^{5-8}$ Furthermore, in practice TD-DFT is applied with approximate exchange-correlation density functionals, since no exact expression is available. Many functionals have systematic deficiencies and lead to bad descriptions for transitions with Rydberg states, longrange charge-transfer, or double-excitations character in the excited state, or even sometimes for single-excitation valence transitions. ${ }^{3}$ Therefore, several extensive tests of various density functionals have been published in order to check their reliability for predicting accurate excited states in the framework of TD-DFT. ${ }^{9-14}$ However, all these benchmarks mainly considered excited stated of organic molecules. In particular, the databases commonly used do not include metallic systems. Meantime, many TD-DFT calculations on metallic particles have been published, particularly concerning noble metal clusters due to their unique optical properties with the well-known plasmon resonance at the nanometric scale. ${ }^{15-29}$ Most calculations were performed with LDA (Local Density Approximation) or standard GGA (Generalized Gradient Approximations) density functionals. To my knowledge, the first comparison of the reliability of density functionals in the prediction of excited states of metallic clusters concerned the calculation of absorption spectra of small silver and nickel $\left(\mathrm{Ag}_{8}, \mathrm{Ni}_{8}, \mathrm{Ag}_{4} \mathrm{Ni}_{4}\right.$ and $\left.\mathrm{Ag}_{11} \mathrm{Ni}_{2}\right)$ clusters for which spectra calculated with BP86, ${ }^{30,31}$ $\mathrm{PBE}^{32}$ and B3LYP ${ }^{33,34}$ functionals were found to be very similar. ${ }^{22,23}$

It is well known that TD-DFT have problems with the calculation of charge-transfer excited states. The excitation are much low and the potential energy curves do not exhibit the correct asymptote (in $1 / \mathrm{R}$ where $\mathrm{R}$ is the distance between the positive and the negative charges of the 
charge-transfer state). This failure has been understood as an electron-transfer self-interaction error by Dreuw and Head-Gordon. ${ }^{3}$ Peach and coworkers have proposed a test for judging the reliability of excitation energies associated with significant charge transfer character thanks to a calculation of the degree of spatial overlap between the occupied and virtual orbitals involved in excitations. ${ }^{35}$ To give a more suitable description of charge-transfer excitations, a long-range correction should be applied to the exchange functional. The Coulomb operator in the LC-approach is split into two parts:

$$
\frac{1}{r_{12}}=\frac{1-\operatorname{erf}\left(\omega r_{12}\right)}{r_{12}}+\frac{\operatorname{erf}\left(\omega r_{12}\right)}{r_{12}}
$$

where $r_{12}$ is the distance between two electrons, and $\omega$ is a range separation parameter. The first term of the right-hand side is a short-range term evaluating with the exchange potential from DFT, while the second term, the long-range part, is evaluating with exact Hartree-Fock exchange. The parameter $\omega$ has been optimized by Hirao et $\mathrm{al}^{36-38}$ and the above partition can be applied in combination with various standard functionals, for example LC-BP86 is the functional resulting from the application of LC-approach to BP86. A recent benchmark ${ }^{11}$ has shown the significant improvements coming from the above correction applied to standard GGA functionals in the description of excited states of small organic molecules. Yanai et al, in an extension of this above approach, have combined the hybrid B3LYP functional at short range with an increasing amount of exact Hartree-Fock exchange at long-range, resulting in a functional named CAM-B3LYP, ${ }^{39}$ which give also good results for charge-transfer excitations. ${ }^{11}$ Such so-called long-range-corrected (LC-) functionals have been used only very recently to investigate the optical properties of metal clusters. $^{28,40-42}$

Using TD-DFT on metal systems like noble metal clusters or transition metal clusters is not easy due to the very large number of excited states in the visible range leading to quasi-continuum spectra when some hundreds electrons are considered (typically ten silver atoms). The presence of many quasi degenerated states leads to severe difficulties in the resolution of equations (problems of convergence in the Davidson diagonalization), and of course a strong computation effort. The use of the LC-approach leads to a strong reduction of the number of calculated excited states in 
the UV-visible range. Indeed, the spectra calculated with a conventional functional (like GGAs) include a large number of spurious states, often with low oscillator strengths, which is thought to be due to a bad description of charge-transfer transitions. These spurious states are removed, or push to higher excitation energies, with the inclusion of long-range corrections. ${ }^{3,40,41}$ For example, The number of states below $6 \mathrm{eV}$ decreases by a factor of about 4 when the long-range corrections are applied to the BP86 functional. For $\mathrm{Ag}_{10} / \mathrm{Ag}_{12}$ clusters, the number of excited states is reduced from $380 / 500$ to $99 / 124 .{ }^{42}$ Thus, the extra computational cost induced by the inclusion of the exact Hartree-Fock exchange is partially offset by the decrease in the number of states.

We present here an assessment of the performance of long-range corrected density functionals for calculating the vertical absorption spectra of silver clusters in the adiabatic linear-response formulation of TD-DFT. The reliability of the TD-DFT predictions will be compared to both experimental spectra and to high-level ab initio calculations performed in the framework of the linear response equation-of-motion coupled cluster (EOM-CC) method. The latter can be considered as a reference method for prediction of transition energies and oscillator strengths for states dominated by single excited configurations, while they give less accurate results for excited states in which doubly excited configurations have a leading role. In experiments, spectra were measured on clusters embedded in rare gas matrix. ${ }^{17,43,44}$ Although condensed rare-gases are the most inert solids, some effects on spectra may be expected. For example, it was shown on both potassium and silver clusters that the dielectric screening for the electron-electron interaction involve a redshift of the plasmon frequency as the dielectric constant of the matrix increases. ${ }^{45}$ Moreover, clusters with differing local environments, known as site isomers, may coexist. Using quantum calculations on sodium clusters embedded in an argon matrix, Gervais et al ${ }^{46,47}$ showed the possible coexistence of several site isomers and rationalized the matrix effects in two competing effects: the dielectric effect leading to a redshift and a confinement of the valence electrons of the clusters due to the presence of the rare-gas atoms leading to a blueshift. Other possible effects concern the eventual deformations of clusters structures during the deposition in matrix, though the deposition energy is low. Finally, some symmetry forbidden transitions may be observed when the cluster is embedded 
due to interaction with the rare-gas atoms. To reduce the matrix effects both the growth of the matrix and measurements of optical spectra are made at low temperature $\left(27 \mathrm{~K},{ }^{17} 6 \mathrm{~K}^{44}\right)$. Previous works have shown that the matrix effects are relatively low, and TDDFT spectra calulated on clusters in gas phase compare well to experimental spectra measured on clusters embedded in rare-gas matrix. ${ }^{17,44}$ We have selected the following functionals representative of several categories: LCBP86,LC- $\omega$ PBE, ${ }^{48}$ LC-M06L, CAM-B3LYP, and $\omega$ B97x. BP86 and PBE are GGA-type functionals. M06L is a local meta-GGA functional ("meta" denotes the inclusion of kinetic energy density, which depends on local derivatives of the spin orbitals) parametrized to have good performances for transition metal chemistry and to satisfy the uniform-electron-gas limit. ${ }^{49}$ LC-BP86 and LC-M06L are obtained by applying the long-range correction of Hirao and coworkers ${ }^{38}$ with $\omega=0.47$ to BP86 and M06L functionals respectively. LC- $\omega$ PBE is obtained from PBE with a parameter $\omega=0.40$. Those LC- functionals contain $0 \%$ Hartree-Fock exchange at short range and $100 \%$ at long range. CAM-B3LYP ${ }^{39}$ and $\omega \mathrm{B} 97 \mathrm{x}^{50}$ are long-range corrected hybrid density functionals. In the case of $\omega \mathrm{B} 97 \mathrm{x}$, the percentage of Hartree-Fock exchange is $16 \%$ at short-range and $100 \%$ at long-range, while CAM-B3LYP comprises of 19\% Hartree-Fock exchange at short-range and $65 \%$ Hartree-Fock at long-range. For all LC- functionals, the $\omega$ dependence on the excitation energies will be presented. We will give also the absorption spectra calculated with some non corrected functionals, namely BP86, M06L and also the hybrid M06-2X. ${ }^{51}$

\section{Methodology}

All calculations were performed with the Gaussian09 suite of programs. ${ }^{52}$ Pre- and post-processing operations were performed by using the graphical interface Gabedit. ${ }^{53}$ The clusters geometries were the lowest-energy structures obtained at BP86 level from Reference. ${ }^{17}$ They were locally optimized with each functional before doing the present calculation of optical properties. All structures are shown in Figure 1. Silver atoms were described through a relativistic effective core potential (called SDD in Gaussian09) so that only 19 valence electrons were treated explicitly. ${ }^{54}$ 
The corresponding basis set was $8 \mathrm{~s} 7 \mathrm{p} 6 \mathrm{~d} 1 \mathrm{f}$ contracted into $6 \mathrm{~s} 5 \mathrm{p} 3 \mathrm{~d} 1 \mathrm{f}$. For the smallest clusters, i.e. $\operatorname{Ag}_{n}$ with $n \leq 8$, we have also calculated the absorption spectra with a quadruple zeta valence + polarization (QZVP) quality basis set. ${ }^{55}$ The spectra were found very similar (they are given in Supplementary Information), and so optical spectra for larger clusters have been calculated with the SDD basis set to reduce the computational effort.

The absorption spectra presented below give the oscillator strength as a function of the excitation energy, together with a curve obtained by a Gaussian broadening (with a full width of half-height of $0.08 \mathrm{eV}$ ). Spectra include calculated excitation energies up to $6 \mathrm{eV}$, though states with multi excitations character, expected to be likely localized beyond about $5 \mathrm{eV}$, are not correctly described in present TDDFT calculations.

For small clusters $\operatorname{Ag}_{n}(n=4,6,8)$, we have performed calculations in the framework of the linear response equation-of-motion coupled cluster (EOM-CCSD) method. For $\mathrm{Ag}_{4}$, the basis set was extended to a quadruple zeta valence + polarization quality, ${ }^{55}$ while the SDD basis set was used for $\mathrm{Ag}_{6}$ and $\mathrm{Ag}_{8}$.

\section{Results and Discussion}

\section{Comparison with experimental spectra}

We first compare our calculated spectra to the experimental ones. For clarity, we only present in Figures 2-5 spectra calculated with BP86, LC-BP86, LC-M06L, CAM-B3LYP and $\omega$ B97X functionals, chosen as representative GGA, LC-GGA, LC-metaGGA, and LC- hybrid functional families respectively. Spectra calculated with M06L, M06-2X, and LC- $\omega$ PBE functionals are given in Supporting Information. In this section, the value of $\omega$ is fixed to the default value in Gaussian09, i.e. $\operatorname{LC}-\omega \operatorname{PBE}(\omega=0.40), \operatorname{LC}-B P 86(\omega=0.47), \operatorname{LC}-\operatorname{M06L}(\omega=0.47), \operatorname{CAM}-B 3 \operatorname{LYP}(\omega=0.33)$, $\omega \operatorname{B} 97 x(\omega=0.30)$. The $\omega$ dependence in results will be discussed in the next section.

We first present briefly some results on neutral silver atom and dimer, before we examine in

details the spectra of silver clusters. As previously observed, ${ }^{15,56}$ the relative energies of excited 
states of silver atom calculated in the framework of TD-DFT are not in complete agreement with available experimental data. The $4 d^{10} 5 s \rightarrow 4 d^{10} 5 p$ excitation energy is calculated to be 3.91 , 3.76, 4.02, 3.75, $4.15 \mathrm{eV}$ at CAM-B3LYP, $\omega$ B97x, LC-M06L, LC-BP86, and BP86 levels respectively, while the experimental values are 3.66 and $3.78 \mathrm{eV}$ for $j=1 / 2$ and $j=3 / 2$ spin-orbit split transitions. ${ }^{57}$ The second allowed excitation correspond to $4 d^{10} 5 s \rightarrow 4 d^{10} 6 p$ transition measured experimentally at the averaged value of $6.005 \mathrm{eV} .{ }^{57}$ The corresponding transitions are calculated at 6.71, 6.60, 7.31, 6.96, and 6.52 eV with CAM-B3LYP, $\omega$ B97x, LC-M06L, LC-BP86, and BP86 functionals respectively. The level energy of the $4 d^{9} 5 s^{2}$ excited state is strongly underestimates whatever the functional used, since the calculated value is $3.49,3.43,3.30,3.66$, and $3.09 \mathrm{eV}$ with CAM-B3LYP, $\omega$ B97x, LC-M06L, LC-BP86 and BP86 functionals respectively, to be compared with the experimental data of 3.75 and $4.30 \mathrm{eV}$ for $j=5 / 2$ and $j=3 / 2$ spin-orbit split transitions. ${ }^{57}$ Hence, the lowest excited state is $4 d^{9} 5 s^{2}$ instead of $4 d^{10} 5 p$. Finally, the level energy of the $4 d^{10} 6 s$ excited state is calculated at 5.17, 4.93, 5.81, 5.51, and 5.27 eV with CAM-B3LYP, $\omega \mathrm{B} 97 \mathrm{x}, \mathrm{LC}-\mathrm{M} 06 \mathrm{~L}, \mathrm{LC}-\mathrm{BP} 86$, and BP86 functionals respectively, while the reference data is 5.28 $\mathrm{eV}^{57}$

For $\mathrm{Ag}_{2}$, the calculated energies of allowed transitions are given in Table 1 together with the experimental data measured on clusters in gas phase or embedded in rare gas matrices. Spectra are given in Supporting Information. Transition energies for the so-called states A and C are correctly calculated with all functionals. The experimental B $\left({ }^{1} \Pi_{u}\right)$ transition at $4.44-4.68 \mathrm{eV}$ is not correctly described with the standard functional BP86 since the transition is calculated at 3.72 $\mathrm{eV}$ with a nearly zero oscillator strength. Previous works have shown that both LDA and B3LYP functionals also fail in the description of that state. ${ }^{44,56}$ In contrast, all LC- functionals describe well the state B. In Table 1, we have assigned the calculated peaks above $5 \mathrm{eV}$ to the so-called D (sometimes with two calculated values) and H states because they are ${ }^{1} \Sigma_{u}^{+}$states. The calculated values strongly overestimate the experimental data of $4.84 \mathrm{eV}$ for $\mathrm{D}$ - $\mathrm{X}$ transition (by more than 1 $\mathrm{eV}$ ), while the calculated state near $7 \mathrm{eV}$ fit well the experimental data of $7.23 \mathrm{eV}$ for $\mathrm{H}$ state.

We now present results on clusters $\mathrm{Ag}_{4}$ to $\mathrm{Ag}_{22}$. In experiments, high resolution spectra of $\mathrm{Ag}_{n}$ 
Table 1: Absorption spectra of $\mathrm{Ag}_{2}$. Energies are given in $\mathrm{eV} .{ }^{a}$ Experimental data in gas phase. ${ }^{58-63} b$ Experimental data in neon matrices ${ }^{44}$

\begin{tabular}{|c|c|c|c|c|c|c|c|}
\hline States & $\operatorname{Expt}^{a}$ & $\mathrm{Expt}^{b}$ & CAM-B3LYP & $\omega \mathrm{B} 97 \mathrm{x}$ & LC-M06L & LC-BP86 & BP86 \\
\hline $\mathrm{A}^{1} \Sigma_{u}^{+}$ & 2.85 & 2.96 & 3.04 & 2.99 & 3.09 & 3.14 & 3.06 \\
\hline $\mathrm{B}^{1} \Pi_{u}$ & 4.44 & 4.68 & 4.40 & 4.34 & 4.51 & 4.48 & 3.72 \\
\hline $\mathrm{C}^{1} \Pi_{u}$ & 4.67 & 4.78 & 4.69 & 4.74 & 4.98 & 4.95 & 4.80 \\
\hline $\mathrm{D}^{1} \Sigma_{u}^{+}$ & 4.84 & 4.85 & $5.86 ; 6.07$ & 6.00 & 6.29 & 6.28 & $5.33 ; 6.37$ \\
\hline $\mathrm{E}^{1} \Pi_{u}$ & 4.98 & 5.07 & & & & & \\
\hline $\mathrm{H}^{1} \Sigma_{u}^{+}$ & 7.23 & & 6.92 & 6.96 & 7.15 & 7.25 & 6.43 \\
\hline
\end{tabular}

$(n=1-9)$ clusters embedded in solid neon matrix have been published very recently, ${ }^{44}$ while spectra of larger clusters are available in solid argon matrix. ${ }^{17,43}$ Absorption spectra calculated for $\mathrm{Ag}_{4}, \mathrm{Ag}_{6}$ and $\mathrm{Ag}_{8}$ clusters are shown in Figure 2 and Figure 3 together with the experimental spectra. We have calculated the absorption spectra with several non LC-functionals, named BP86, M06L, M06-2X, PBE, and B3LYP, but as the spectra are found to be very similar, we only show in Figure 2 and Figure 3 the spectra calculated at the BP86 level (Other spectra can be found in Supporting Information). The long-range correction applied to BP86, giving the LC-BP86 functional, leads to significant changes in the absorption spectra. First, the number of excited states below $6 \mathrm{eV}$ is strongly reduced. Second, the shape of the spectra is modified. The main peaks are blueshifted from 2.95 to $3.18 \mathrm{eV}$ for $\mathrm{Ag}_{4}$, from 3.23 to $3.77 \mathrm{eV}$ for $\mathrm{Ag}_{6}$, and from 3.82 to 4.13 for $\mathrm{Ag}_{8}$ ( $T_{d}$ isomer). Interestingly, for $\mathrm{Ag}_{6}$ a new peak at $3.26 \mathrm{eV}$ is obtained with LC-BP86. It does not correspond to any transitions of the BP86 spectrum. Similarly, for $\operatorname{Ag}_{8}\left(T_{d}\right.$ isomer) the LC-BP86 spectrum presents two small peaks at 3.17 and $3.47 \mathrm{eV}$, in contrast with the BP86 spectrum which has only one peak at $2.99 \mathrm{eV}$. The spectra calculated at LC-BP86 level seem to be in better agreement with the experimental spectra though the agreement is not perfect. For $\mathrm{Ag}_{4}$, the experimental data show two main transitions at 3.07 and $4.23 \mathrm{eV}$, in correct agreement with the LC-BP86 spectrum. The experimental spectrum of $\mathrm{Ag}_{6}$ shows a main peak at $3.45 \mathrm{eV}$ with a second less intense one at $3.65 \mathrm{eV}$ (Figure 2). The latter could correspond to the peak at 3.26 $\mathrm{eV}$ in the LC-BP86 spectrum. For $\mathrm{Ag}_{8}$, two different structures of symmetry $T_{d}$ and $D_{2 d}$ compete for the lowest-energy isomer (see Figure 1). Previous studies have shown that the ordering is de- 
pendent on both the basis set and the functional used. ${ }^{17,64-66}$ In the present study, the $T_{d}$ structure is found to be the lowest-energy isomer at BP86, M06-2X, LC-BP86, LC- $\omega$ PBE, CAM-B3LYP and $\omega \mathrm{B} 97 \mathrm{x}$ levels, while at M06L and LC-M06L levels the $T_{d}$ structure lies $0.01 \mathrm{eV}(0.03 \mathrm{eV}$ at LC-M06L/QZVP level) above the $D_{2 d}$ isomer. The experimental spectrum of $\mathrm{Ag}_{8}$ presents two small narrow peaks at 3.12 and $3.20 \mathrm{eV}$ and two intense transitions at 3.65 and $4.00 \mathrm{eV}$. Three transitions (at 3.12, 3.20 and $4.00 \mathrm{eV}$ respectively) could correspond to transitions calculated at LC-BP86 level for the $T_{d}$ isomer, while the experimental intense transitions at 3.65 and $4.00 \mathrm{eV}$ are well reproduced by transitions calculated for the $D_{2 d}$ isomer at 3.88 and $4.11 \mathrm{eV}$ respectively. As previously suggested, ${ }^{17}$ both isomers could be likely present in the experiment, the experimental spectrum being then a sum of the spectra for both isomers. The spectra of $\mathrm{Ag}_{4}, \mathrm{Ag}_{6}$ and $\mathrm{Ag}_{8}$ calculated at LC-M06L level are similar to those obtained at LC-BP86 but with a redshift of about $0.1 \mathrm{eV}$. Finally, the transitions calculated with the long-range corrected hybrid density functionals, CAM-B3LYP and $\omega$ B97x, are redshifted by about $0.1 \mathrm{eV}$ with respect to those obtained at LC-M06L, and are in better agreement with the experimental data. However, a disagreement with the experimental spectrum of $\mathrm{Ag}_{6}$ remains: the small peak is shifted on the low energy side of the main transition to about $3.0 \mathrm{eV}$ (versus $3.65 \mathrm{eV}$ in experiment).

Interestingly, we have calculated the mean absolute deviations (MADs) from the experiment. The MADs were calculated using only the main transitions for each size. Both experimental data and calculated values which were used in the calculation of MADs are given in a Table in Supporting Information. We should note that the experimental spectra present also various less intense structures, that do not appear clearly in plots of Figure 2 and Figure 3, but were well identified in the original paper. ${ }^{44}$ For clarity, we will not discuss the position of all peaks, while they are roughly well described by the present calculations. Calculations with the BP86 functional produce an average deviation of $0.21 \mathrm{eV}, \mathrm{M} 06 \mathrm{~L}$ is a little better, while the hybrid M06-2X leads to a relatively large MAD $(0.32 \mathrm{eV})$ due to a systematic redshift of the main transitions. CAM-B3LYP and $\omega \mathrm{B} 97 \mathrm{x}$ functionals, with MADs of 0.05 and $0.07 \mathrm{eV}$ respectively, are clearly the best functionals, and even outperform the present EOM-CCSD predictions. 
Table 2: Mean absolute deviations (in $\mathrm{eV}$ ) from the experiment. MAD1 is calculated with the main transitions of spectra of $\mathbf{A g}_{n}$ clusters with $n=4,6,8$. MAD2 is calculated with the main transitions of spectra of $\mathbf{A g}_{n}$ clusters with $n=4,6,8,12$. MAD3 is calculated with the main transitions of spectra of $\mathbf{A g}_{n}$ clusters with $n=4,6,8,12,18,20$. Present values of $\boldsymbol{\omega}$ are the default values in Gaussian09.

\begin{tabular}{llll}
\hline & MAD1 & MAD2 & MAD3 \\
\hline BP86 & 0.21 & 0.30 & 0.29 \\
M06L & 0.16 & 0.20 & 0.20 \\
M06-2X & 0.32 & 0.34 & 0.29 \\
LC- $\omega$ PBE $(\omega=0.40)$ & 0.12 & 0.10 & 0.12 \\
LC-BP86 $\omega=0.47)$ & 0.19 & 0.18 & 0.21 \\
LC-M06L $(\omega=0.47)$ & 0.12 & 0.12 & 0.16 \\
CAM-B3LYP $(\omega=0.33)$ & 0.05 & 0.05 & 0.08 \\
$\omega B 97 x(\omega=0.30)$ & 0.07 & 0.07 & 0.09 \\
EOM-CCSD & 0.10 & & \\
\hline
\end{tabular}

Figure 4 shows the calculated absorption spectra of $\mathrm{Ag}_{10}$ and $\mathrm{Ag}_{12}$ clusters. For $\mathrm{Ag}_{10}$, the BP86 spectrum gives a main peak at $3.08 \mathrm{eV}$ followed by a very large structure without dominant transition. In contrast, spectra calculated with LC-functionals present two main transitions (for examples at 3.32 and $4.32 \mathrm{eV}$ for CAM-B3LYP, and 3.30 and 3.99 for $\omega \mathrm{B} 97 \mathrm{x}$ respectively), and a small peak (at 3.90 and $4.49 \mathrm{eV}$ for CAM-B3LYP and $\omega$ B97x respectively). In experiment, the formation of the $\mathrm{Ag}_{10}$ cluster is unfavorable and only one spectrum can be found in the litterature. ${ }^{17}$ Although the signal to noise ratio of the experimental spectrum is low, it shows three distinct narrow lines at 3.79, 3.98 and $4.15 \mathrm{eV}$, which could correspond to the present three peaks. However, the experimental spectrum should be confirmed because its similarities with the spectrum of $\mathrm{Ag}_{9}$ suggest a fragmentation of $\mathrm{Ag}_{10}$ into $\mathrm{Ag}_{9}+\mathrm{Ag}$ atoms after the mass selection, so that the spectrum could be associated to $\mathrm{Ag}_{9}$ cluster. ${ }^{17}$ For $\mathrm{Ag}_{12}$, the experimental spectrum, which presents three strong lines at $3.42,3.91$, and $4.38 \mathrm{eV},{ }^{17}$ is well reproduced by all calculations. In particular, the predictions of CAM-B3LYP $(3.41,3.96$, and $4.27 \mathrm{eV})$ and $\omega \mathrm{B} 97 \mathrm{x}(3.41,3.84$, and $4.24 \mathrm{eV})$ are in excellent agreement with the experimental data. In Table 2, the mean deviation called MAD2 includes the spectrum of $\mathrm{Ag}_{12}$ in the reference set in addition to those of $\mathrm{Ag}_{4}, \mathrm{Ag}_{6}$ and $\mathrm{Ag}_{8}$. $\mathrm{The}$ deviation for BP86 calculations strongly increases due to a redshift of $0.4 \mathrm{eV}$ in the prediction of the spectrum of $\mathrm{Ag}_{12}$ versus the experiment. 
The absorption spectra of large $\operatorname{Ag}_{n}(n=15-25)$ clusters are characterized by the emergence of a dominant and relatively broad peaks between 3.5 and $4.0 \mathrm{eV}$, sometimes accompanied by one or two absorption peaks at higher energies but smaller intensities. ${ }^{17,43}$ The features are similar to the plasmon excitation observed in metal nanoparticles of several $\mathrm{nm}$ in diameter and previously interpreted as collective excitations of valence $s$-electrons. However, in the case of noble metal, the polarization effects of the $d$-electrons were showed to greatly influence the optical response. In particular, the core polarization screens the valence electron interaction and leads to a redshift of the surface plasmon energy. ${ }^{67,68}$ Recently, the optical response of medium-sized $(n=15-$ 22) clusters has been associated to excitation of $d$-electrons from calculations using GGA-type functionals. ${ }^{17,18,21}$ In Figure 5 we give the calculated spectra for the $\mathrm{Ag}_{18}, \mathrm{Ag}_{20}$, and $\mathrm{Ag}_{22}$ clusters. For $\mathrm{Ag}_{18}$, the experimental spectrum shows a large band centered at $3.62 \mathrm{eV}$ with a shoulder at $4.04 \mathrm{eV} .{ }^{43}$ Spectra calculated with LC-functionals reproduce rather well the experimental ones but with a blueshift of about $0.1-0.3 \mathrm{eV}$, the main band being centered at 3.90, 3.90, 3.80 and 3.72 $\mathrm{eV}$ with LC-BP86, LC-M06L, CAM-B3LYP and $\omega$ B97x functionals respectively. For $\mathrm{Ag}_{20}$, the experimental spectrum presents a main transition at $3.70 \mathrm{eV}$ and a less-intense peak at $3.97 \mathrm{eV} .{ }^{43}$ The calculated spectra are blueshifted by $0.18-0.39 \mathrm{eV}$. The best predictions are those from CAMB3LYP $(3.88 \mathrm{eV})$ and $\omega \mathrm{B} 97 \mathrm{x}(3.91 \mathrm{eV})$ calculations. The band width of the spectrum for $\mathrm{Ag}_{20}$ is narrower than that for $\mathrm{Ag}_{18}$ whatever the functional used, in good agreement with the experiment. For $\mathrm{Ag}_{22}$, all calculated spectra present two main bands visible in Figure 5 (centered at 3.80 and $4.05 \mathrm{eV}$ at CAM-B3LYP level and at 3.83 and $4.13 \mathrm{eV}$ for $\omega \mathrm{B} 97 \mathrm{x}$ level). To my knowledge, no experimental spectrum is available for comparison. The mean deviation of calculated peaks versus experimental ones confirms the good performances of CAM-B3LYP and $\omega$ B97x functionals (see MAD3 in Table 2), while LC-BP86 and LC-M06L functional are less accurate for large clusters $\left(\mathrm{Ag}_{18}\right.$ and $\left.\mathrm{Ag}_{20}\right)$. 


\section{Description of plasmon like band}

Interestingly, spectra calculated with the BP86 functional for $\mathrm{Ag}_{18}$ and $\mathrm{Ag}_{20}$ are very different than those obtained with LC-functionals. They present some strongly broadened and damped bands resulting in very large structures. The spectra are biased by many spurious states beyond $3 \mathrm{eV}$. The BP86 spectra do not reproduce well the plasmon-like bands of experimental spectra because a strong bottom signal still exists beyond $4 \mathrm{eV}$ while no transition is measured in experiments. The same feature are found with other GGA-type functionals, and also with M06L (Spectra are given in Supporting Information). The long-range correction appears here to be essential in describing the absorption of large metallic clusters. In previous works, ${ }^{17,40}$ the spectra calculated with non LC-functionals (like BP86 or PBE) were found to better reproduce the experimental spectra than present BP86 calculations do. It was due to the use of the small LANL2DZ basis set which is not large enough to calculate states beyond $4 \mathrm{eV}$ (including spurious states), and also a truncation in the spectra at about $4 \mathrm{eV}$. But when calculations are made up to $5 \mathrm{eV}$ and with a more suitable basis set, many spurious states appear beyond the plasmon band. Moreover, at GGA level the main transitions are due to the excitations from orbitals, with a shape associated to $s$ and $d$ contributions, to the outer region with an $s+p$ character distributed on the whole cluster. For $\operatorname{Ag}_{20}$, important contributions come from inner $d$-orbitals HOMO- $n, n=6-30$. In contrast, the role of $d$-electrons are less important in calculations with LC-functionals since the transitions are mainly due to excitations from HOMO- $n(n=0-5) s$-type orbitals. The excitations from $d$-orbitals to the outer region distributed on the whole clusters are pushed to much higher energies. Since they present a long-range charge-transfer character, these excitations are properly described only with a correct asymptotic potential. The description of the plasmon band with LC-functionals is in better agreement with the classical interpretation as a collective excitation of valence $s$-electrons. We can conclude that the use of LC- functionals should be preferred for a good description of plasmon like band. 


\section{Importance of the $\omega$ value}

To complete the study, Figure 6 presents the number of states calculated by each functional below a threshold of $6 \mathrm{eV}$, together with the sum of oscillator strengths below the same threshold. As expected, the number of states calculated with a standard functional, like BP86, is very large. The long-range correction, implying the exact Hartree-Fock exchange, reduces significantly the number of states. For example, in the case of $\mathrm{Ag}_{12}$, the number of calculated states is reduced from 500 to 115 when the long-range correction is applied to BP86. It is interesting to note that the sum of oscillator strengths calculated at BP86 and LC-BP86 levels are roughly similar. Actually, the long-range correction increases significantly the oscillator strengths of dominant transitions (see for example LC-BP86 spectra versus BP86s in Figure 4), while it removes a large number of states with low (frequently zero) oscillator strengths. The combination of these two effects leads to a quasi conservation of the sum of oscillator strengths. The inclusion of Hartree-Fock exchange at long-range in the functional is clearly responsible of the removing of many spurious states, it pushes the charge-transfer states to higher excitation energies or eliminates them. Hence BP86 calculates a large number of spurious states with low oscillator forces (but sometimes leading to a damping of absorption bands) which are likely not to be located in this energy range of the absorption spectrum. The elimination of spurious charge-tansfer states using LC-functionals has been already discussed in previous works, ${ }^{3,36,37,39}$ indicating that a correct description of optical properties needs a correct asymptotic behavior of the exchange potential. Interestingly, Figure 6 shows that the LC-hybrid functionals CAM-B3LYP and $\omega$ B97x calculate more states than LCBP86 and LC-M06L functionals. For instance, in the case of $\mathrm{Ag}_{22}$, CAM-B3LYP and $\omega$ B97x calculates 443 and 345 states respectively, while LC-BP86 and LC-M06L calculate 250 and 205 states respectively. In the case of CAM-B3LYP, the long-range part uses at most $60 \%$ HartreeFock exchange, and so the long-range asymptotic behavior of the charge-transfer states is not fully corrected. This could explain why many spurious states are not removed. However, the calculated spectra at CAM-B3LYP and $\omega$ B97x levels reproduce very well the experimental spectra.

We have studied the $\omega$ dependence in the excitation spectra for several functionals. For LC- 
M06L, in addition to the last optimized value of $0.47,{ }^{38}$ we have tested the original value of 0.33 suggested by Hirao et al., ${ }^{36}$ and also $0.15,0.60$ and 0.80 . For the main peaks, a blueshift of about $0.3 \mathrm{eV}$ together with an increase of about $30 \%$ of their oscillator strengths are observed with increasing $\omega$ from 0.15 to 0.80 . Meantime, the number of states is strongly reduced (see Figure 7). All calculated spectra are in Supporting Information. Table 3 indicate that the value of 0.33 leads to the smallest MAD (0.09). A value of 0.60 lead to a MAD of 0.20 , similar to that calculated for the non corrected M06L $(\omega=0)$ functional. A large part of exact exchange at short range is then not suitable. Interestingly, we have studied the effect of the $\omega$ value on $4 d^{10} 5 s \rightarrow 4 d^{10} 5 p$ and $4 d^{10} 5 s$ $\rightarrow 4 d^{9} 5 s^{2}$ excitation energies for a single atom. The former transition is calculated to increase from 3.23 to $4.21 \mathrm{eV}$ with increasing $\omega$ value from 0.05 to 1.0 , while the latter decrease from 4.15 down to $3.83 \mathrm{eV}$. The best agreement with the experimental data is obtained for $\omega$ in the $0.8-0.9$ range, where the $4 d^{10} 5 p$ state become lower than the $4 d^{9} 5 s^{2}$ state. Unfortunately, the value of $\omega=0.80$ leads to rather bad results when used to calculate spectra for clusters of several atoms (MAD of $0.23 \mathrm{eV}$, see Table 3). This result shows that fitting the value of $\omega$ on excitation energies on a single atom does not necessary lead to good spectra on clusters. For LC- $\omega$ PBE, we have also found a small blueshift of the main peaks with increasing $\omega$, the value of 0.40 give the smallest MAD. We have also tested several values of $\omega$ in the case of hybrid CAM-B3LYP and $\omega$ B97x functionals, without changing the other functionals' parameters. The $\omega$ dependence was found to be relatively small. The original values, 0.33 and 0.30 for CAM-B3LYP and $\omega$ B97x respectively, are found to be the best chooses.

\section{Conclusions}

Absorption spectra of silver clusters $\operatorname{Ag}_{n}(n=4-22)$ have been calculated in the framework of the adiabatic linear-response formulation of TD-DFT using various long-range corrected density functionals. The performances of functionals have been evaluated with comparison of their predictions on isolated clusters to available experimental data measured on clusters embedded in rare gas 
Table 3: Variations of mean absolute deviations (in $\mathrm{eV}$ ) from the experiment with the value of $\omega$. See Table 2 for the definition of MAD1, MAD2, MAD3.

\begin{tabular}{llll}
\hline & MAD1 & MAD2 & MAD3 \\
\hline LC-M06L $(\omega=0.15)$ & 0.08 & 0.11 & 0.11 \\
LC-M06L $(\omega=0.33)$ & 0.07 & 0.07 & 0.09 \\
LC-M06L $(\omega=0.47)$ & 0.12 & 0.12 & 0.16 \\
LC-M06L $(\omega=0.60)$ & 0.15 & 0.15 & 0.20 \\
LC-M06L $(\omega=0.80)$ & 0.17 & 0.17 & 0.23 \\
LC- $\omega P B E(\omega=0.20)$ & 0.12 & 0.14 & 0.12 \\
LC- $\omega P B E(\omega=0.40)$ & 0.12 & 0.10 & 0.12 \\
LC- $\omega P B E(\omega=0.60)$ & 0.21 & 0.18 & 0.20 \\
CAM-B3LYP $(\omega=0.15)$ & 0.08 & 0.08 & \\
CAM-B3LYP $(\omega=0.33)$ & 0.05 & 0.05 & 0.08 \\
CAM-B3LYP $(\omega=0.45)$ & 0.06 & 0.09 & \\
$\omega B 97 x(\omega=0.15)$ & 0.12 & 0.07 & \\
$\omega B 97 x(\omega=0.30)$ & 0.07 & 0.07 & 0.09 \\
$\omega B 97 x(\omega=0.45)$ & 0.12 & 0.09 & \\
\hline
\end{tabular}

matrix. Calculated spectra are found to be in good agreement with experimental spectra though calculations on single atom and dimer do not reproduce well the experimental data. For main transitions, the mean deviation from the experiment is found to be less than $0.2 \mathrm{eV}$ with the five longrange corrected functionals of interest, namely LC-BP86, LC- $\omega$ PBE, LC-M06L, CAM-B3LYP and $\omega \mathrm{B} 97 \mathrm{x}$. In particular, very good results both on position of peaks and oscillator strengths, are obtained with the LC-hybrid functionals CAM-B3LYP and $\omega$ B97x indicating that a portion of exact Hartree-Fock exchange at short range improves the predictions. LC-M06L (with $\omega=0.33$ ) and LC- $\omega$ PBE (with $\omega=0.40$ ) give also very good results. As LC-M06L calculates fewer states, it could be competitive for calculating the spectra of very large clusters not accessible with LChybrid functionals. For large clusters, the long-range correction appears to be essential in describing the absorption spectra, since the calculated spectra with non corrected functionals do not reproduce well the plasmon-like excitation and strongly overestimate the role of $d$ electrons in transitions. The description of the plasmon band with LC-functionals, as transitions associated to excitations from $s$ orbitals to $s+p$ orbitals, is in fairly good agreement with the classical interpretation as a collective excitation of valence $s$-electrons. The present results show that LC-functionals should be preferred to simulate the spectra of large clusters. 


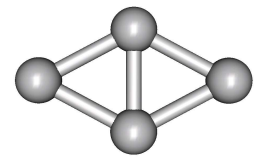

$\operatorname{Ag}_{4}\left(D_{2 h}\right)$

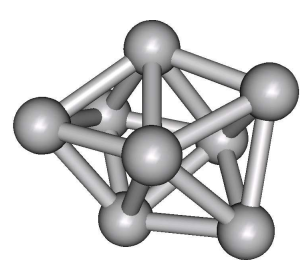

$\operatorname{Ag}_{8}\left(\mathbf{D}_{2 d}\right)$

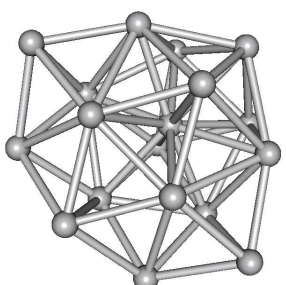

$\operatorname{Ag}_{18}\left(C_{s}\right)$

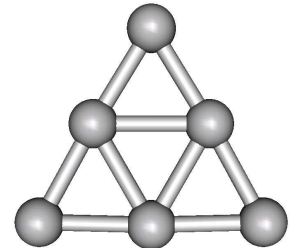

$\operatorname{Ag}_{6}\left(\mathbf{D}_{3 \mathrm{~h}}\right)$

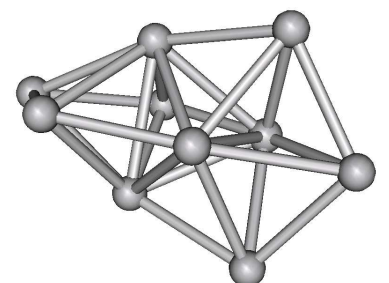

$\operatorname{Ag}_{10}\left(\mathbf{D}_{2 \mathrm{~d}}\right)$

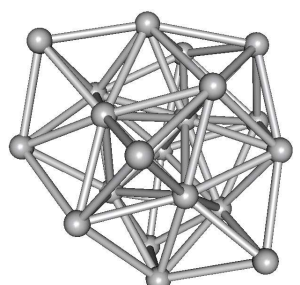

$\operatorname{Ag}_{20}\left(C_{s}\right)$

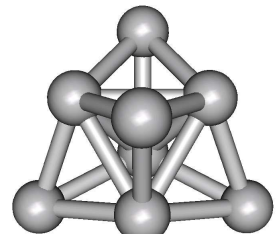

$\operatorname{Ag}_{8}\left(T_{d}\right)$

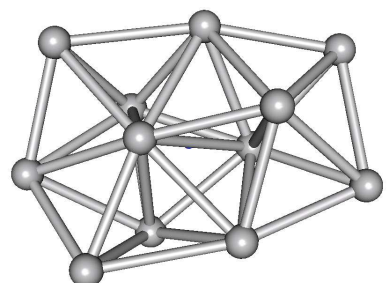

$\operatorname{Ag}_{12}\left(C_{s}\right)$

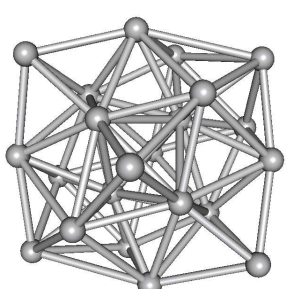

$\operatorname{Ag}_{22}\left(\mathrm{C}_{1}\right)$

Figure 1: Structures of lowest-energy isomers of $\mathrm{Ag}_{n}$ clusters.

\section{Acknowledgement}

The author thanks the Pôle Scientifique de Modélisation Numérique (PSMN) at Lyon, France, and the GENCI-IDRIS(Grant i2013086864) center for generous allocation of computational time.

\section{Supporting Information Available}

This information is available free of charge via the Internet at http://pubs.acs.org. 

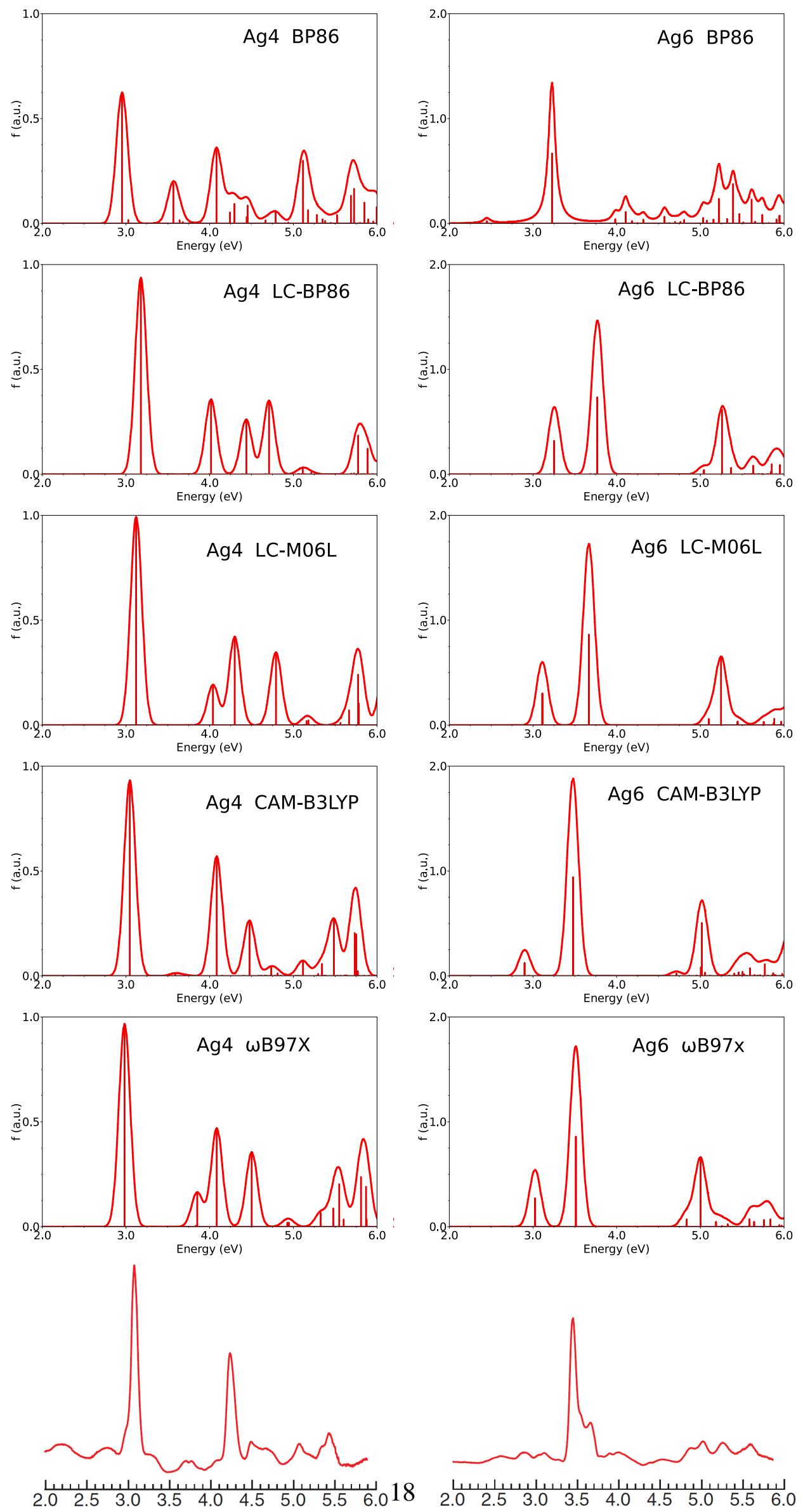

Figure 2: Absorption spectra of $\operatorname{Ag}_{4}\left(D_{2 h}\right.$ symmetry) and $\operatorname{Ag}_{6}$ ( $D_{3 h}$ symmetry) clusters. Plots of the experimental results (last row) were generated using digitizing software on the original spectra. ${ }^{44}$ 

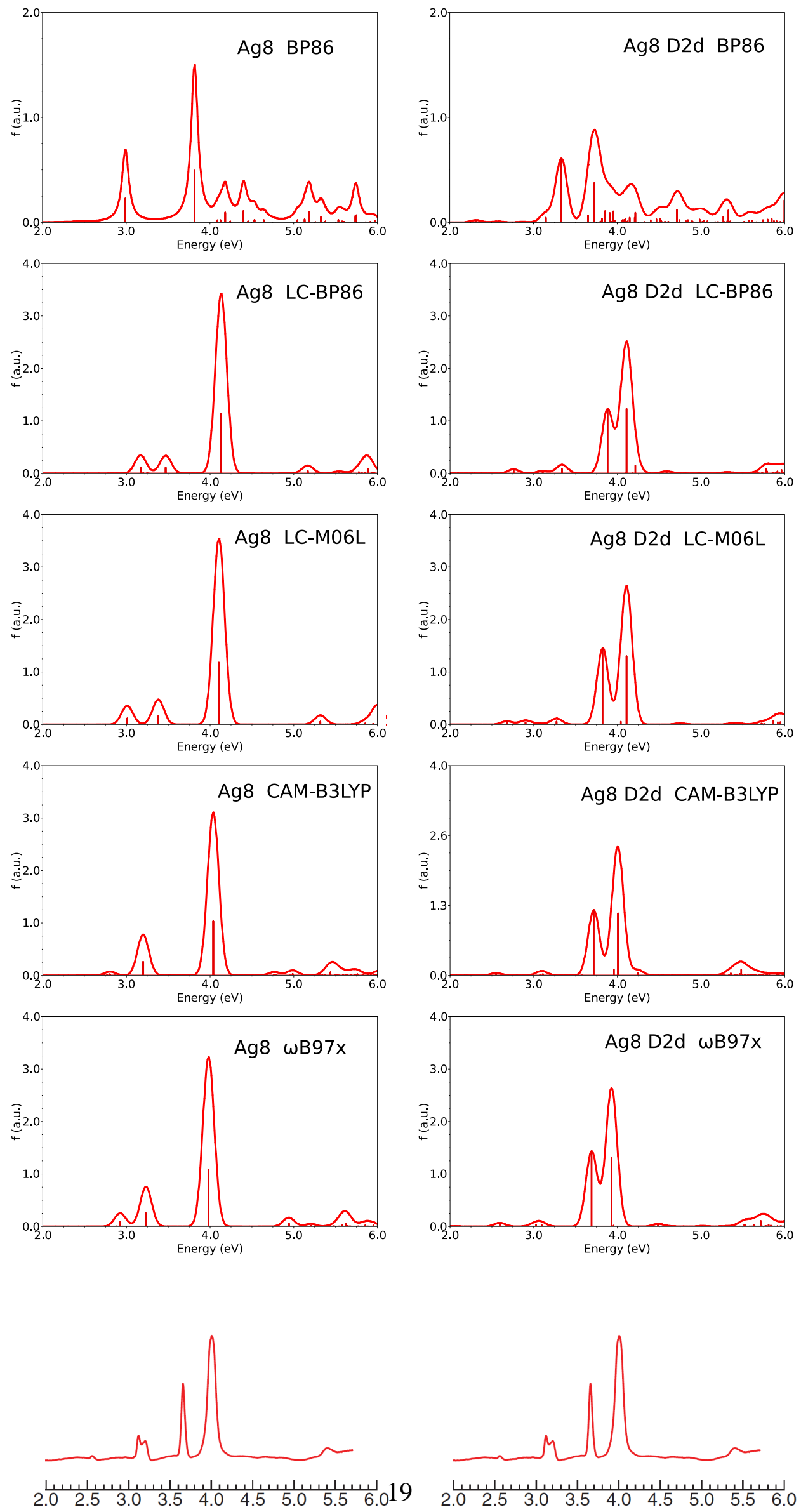

Figure 3: Absorption spectra of $\mathrm{Ag}_{8}\left(T_{d}\right.$ symmetry in first column, $D_{2 d}$ symmetry in the second column). The lowest-energy isomer is the $T_{d}$ structure at BP86, LC-BP86, CAM-B3LYP and $\omega \mathrm{B} 97 \mathrm{x}$ levels, while it is the $D_{2 d}$ isomer at the LC-M06L level. Plots of the experimental results (last row) were generated using digitizing software on the original spectra. ${ }^{44}$ 

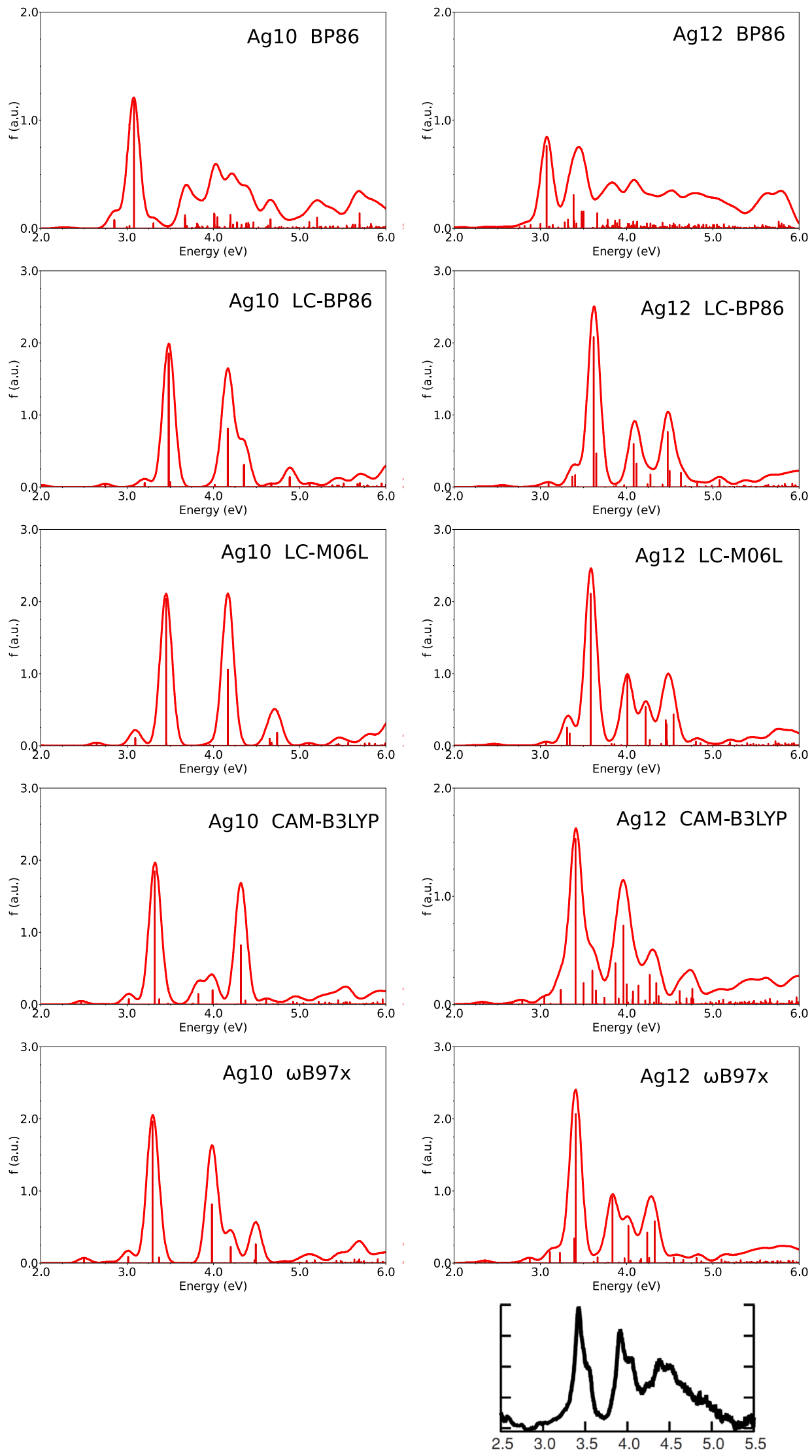

Figure 4: Absorption spectra of $\operatorname{Ag}_{10}\left(D_{2 d}\right.$ symmetry) and $\operatorname{Ag}_{12}\left(C_{s}\right.$ symmetry). Plot of the experimental spectrum (last row) was generated using gigitizing software on the original spectra. ${ }^{17}$ 

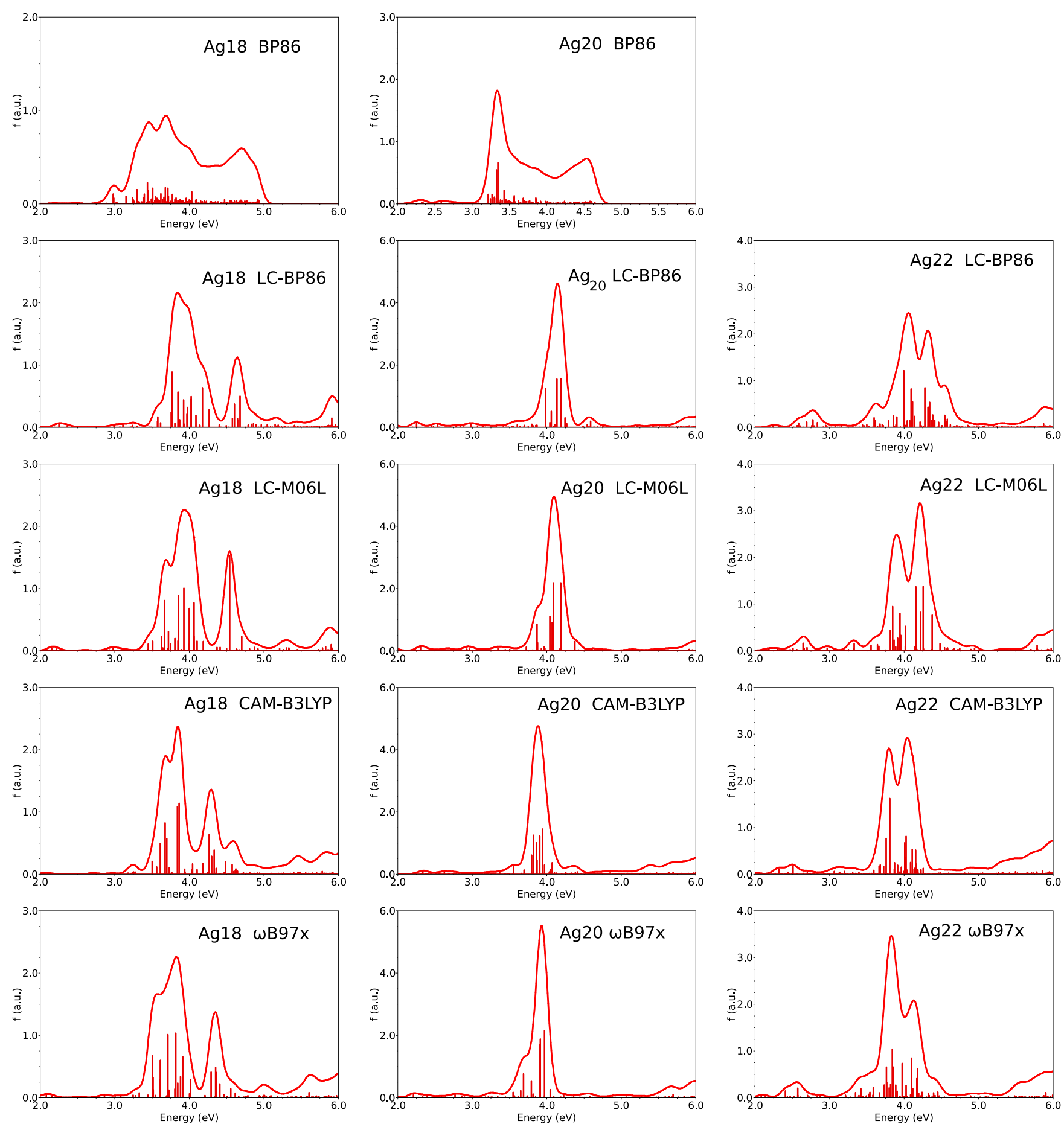

Figure 5: Absorption spectra of $\mathrm{Ag}_{18}, \mathrm{Ag}_{20}$ and $\mathrm{Ag}_{22}$. 

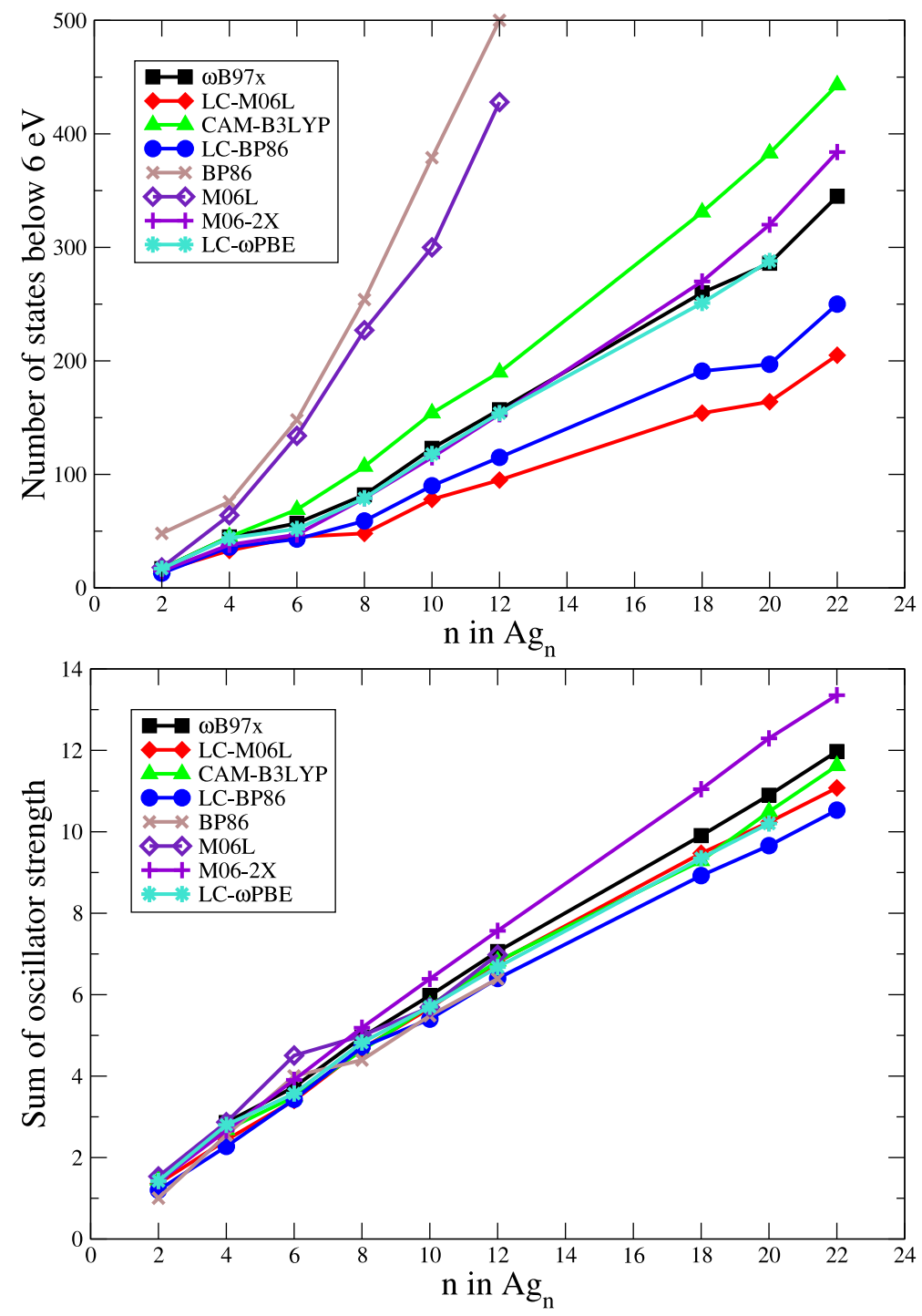

Figure 6: Number of states below $6.0 \mathrm{eV}$ and the sum of oscillator strengths below a threshold energy of $6.0 \mathrm{eV}$. The value of $\omega$ is $\omega \mathrm{B} 97 \mathrm{x}(\omega=0.30), \operatorname{LC}-\operatorname{M} 06 \mathrm{~L}(\omega=0.47), \mathrm{CAM}-\mathrm{B} 3 \operatorname{LYP}(\omega=0.33)$, LC-BP86 $(\omega=0.47), \operatorname{LC}-\omega \operatorname{PBE}(\omega=0.40)$. 

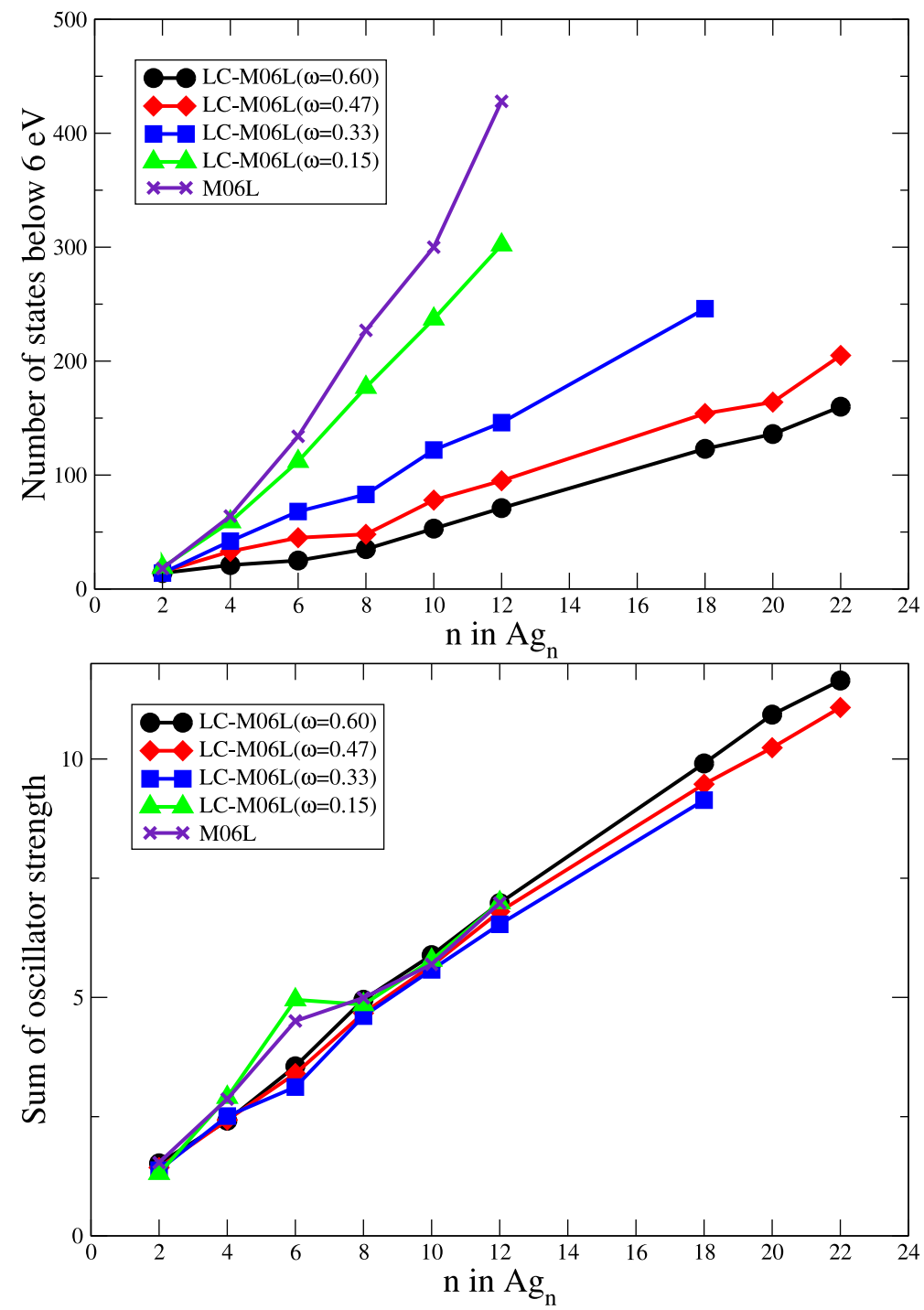

Figure 7: Number of states below $6.0 \mathrm{eV}$ and the sum of oscillator strengths below a threshold energy of $6.0 \mathrm{eV}$ using the LC-M06L functional. 


\section{References}

(1) Runge, E.; Gross, E. K. U. Phys. Rev. Lett. 1984, 52, 997-1000.

(2) van Leeuwen, R. Int. J. Mod. Phys. B 2001, 15, 1969-2023.

(3) Dreuw, A.; Head-Gordon, M. Chem. Rev. 2005, 105, 4009-4037.

(4) Casida, M. E. in Recent Advances in Density Functional Methods. Part I, p. 155; D.P. Chong Ed. (Singapore, World Scientific), 1995.

(5) Maitra, N. T.; Zhang, F.; Cave, R. J.; Burke, K. J. Chem. Phys. 2004, 120, 5932-5937.

(6) Huix-Rotllant, M.; Ipatov, A.; Rubio, A.; Casida, M. E. Chem. Phys. 2011, 391, 120-129.

(7) Ziegler, T.; Seth, M.; Krykunov, M.; Autschbach, J.; Wang, F. J. Mol. Struct.: THEOCHEM 2009, 914, 106-109.

(8) Ziegler, T.; Krykunov, M. J. Chem. Phys. 2010, 133, 074104.

(9) Silva-Junior, M. R.; Schreiber, M.; Sauer, S. P. A.; Thiel, W. J. Chem. Phys. 2008, 129, 104103.

(10) Rohrdanz, M. .; Herbert, J. M. J. Chem. Phys. 2008, 129, 034107.

(11) Jacquemin, D.; Wathelet, V.; Perpete, E. A.; Adamo, C. J. Chem. Theory Comput. 2009, 5, $2420-2435$.

(12) Caricato, M.; Trucks, G. W.; Frisch, M. J.; Wiberg, K. B. J. Chem. Theory Comput. 2010, 6, $370-383$.

(13) Send, R.; Kühn, M.; Furche, F. J. Chem. Theory Comput. 2011, 7, 2376-2386.

(14) Jacquemin, D.; Planchat, A.; Adamo, C.; Menneucci, B. J. Chem. Theory Comput. 2012, 8, $2359-2372$. 
(15) Yabana, K.; Bertsch, G. F. Phys. Rev. A 1999, 60, 3809-3814.

(16) Zhao, G. F.; Lei, Y.; Zeng, Z. Chem. Phys. 2006, 327, 261-268.

(17) Harb, M.; Rabilloud, F.; Simon, D.; Rydlo, A.; Lecoultre, S.; Conus, F.; Rodrigues, V.; Felix, C. J. Chem. Phys. 2008, 129, 194108.

(18) Baisha, K.; Idrobo, J. C.; Ogut, S.; Yang, M.; Jackson, K.; Jullinek, J. Phys. Rev. B 2008, 78, 075439.

(19) Harb, M.; Rabilloud, F.; Simon, D. Chem. Phys. Lett. 2007, 449, 38-43.

(20) Aikens, C. M.; Li, S.; Schatz, G. C. J. Phys. Chem. C 2008, 112, 11272-11279.

(21) Harb, M.; Rabilloud, F.; Simon, D. Chem. Phys. Lett. 2009, 476, 186-190.

(22) Harb, M.; Rabilloud, F.; Simon, D. J. Chem. Phys. 2009, 131, 174302.

(23) Harb, M.; Rabilloud, F.; Simon, D. Phys. Chem. Chem. Phys. 2010, 12, 4246-4254.

(24) Weissker, H. C.; Mottet, C. Phys. Rev. B 2011, 84, 165443.

(25) Durante, N.; Fortunelli, A.; Broyer, M.; Stener, M. J. Phys. Chem. C 2011, 115, 6277-6282.

(26) Baisha, K.; Idrobo, J. C.; Ogut, S.; Yang, M.; Jackson, K.; Jullinek, J. Phys. Rev. B 2011, 83, 245402.

(27) Koppen, J. V.; Hapka, M.; Szczesniak, M. M.; Chalasinski, G. J. Chem. Phys. 2012, 137, 114302.

(28) Bae, G. T.; Aikens, C. M. J. Phys. Chem. A 2012, 116, 8260-8269.

(29) Rabilloud, F. Eur. Phys. J. D 2013, 67, 18.

(30) Becke, A. D. Phys. Rev. A 1988, 38, 3098-3100.

(31) Perdew, J. P. Phys. Rev. B 1986, 33, 8822-8824. 
(32) Perdew, J. P.; Burke, K.; Ernzerhof, M. Phys. Rev. Lett. 1996, 77, 3865-3868.

(33) Becke, A. D. J. Chem. Phys. 1993, 98, 5648-5652.

(34) Lee, C.; Yang, W.; Parr, R. G. Phys. Rev. B 1988, 37, 785-789.

(35) Peach, M. J. G.; Benfield, P.; Helgaker, T.; Tozer, D. J. J. Chem. Phys. 2008, 128, 044118.

(36) Iikura, H.; Tsuneda, T.; Yanai, T.; Hirao, K. J. Chem. Phys. 2001, 115, 3540-3544.

(37) Tawada, Y.; Tsuneda, T.; Yanagisawa, S.; Yanai, T.; Hirao, K. J. Chem. Phys. 2004, 120, $8425-8433$.

(38) Song, J.-W.; Hirosawa, T.; Tsuneda, T.; Hirao, K. J. Chem. Phys. 2007, 126, 154105.

(39) Yanai, T.; Tew, D. P.; Handy, N. C. Chem. Phys. Lett. 2004, 393, 51-57.

(40) Silverstein, D. W.; Jensen, L. J. Chem. Phys. 2010, 132, 194302.

(41) Harb, M.; Rabilloud, F.; Simon, D. J. Phys. B: At. Mol. Opt. Phys. 2011, 44, 035101.

(42) Rabilloud, F. Recent. Res. Devel. Chem. Physics 2012, 6, 67-77.

(43) Fedrigo, S.; Harbich, W.; Buttet, J. Phys. Rev. B 1993, 47, 10706-10715.

(44) Lecoultre, S.; Rydlo, A.; Buttet, J.; Felix, C.; Gilb, S.; Harbich, W. J. Chem. Phys. 2011, 134, 184504.

(45) Rubio, A.; Serra, L. Phys. Rev. B 1993, 48, 18222-18229.

(46) Gervais, B.; Giglio, E.; Jacquet, E.; Ipatov, A.; Reinhard, P.-G.; Fehrer, F.; Suraud, E. J. Chem. Phys. 2004, 121, 8466-8480.

(47) Gervais, B.; Giglio, E.; Jacquet, E.; Ipatov, A.; Reinhard, P.-G.; Fehrer, F.; Suraud, E. Phys. Rev. A 2005, 71, 015201.

(48) Vydrov, O. A.; Heyd, J.; Krukau, A. V.; Scuseria, G. E. J. Chem. Phys. 2006, 125, 074106. 
(49) Zhao, Y.; Truhlar, D. G. J. Chem. Phys. 2006, 125, 194101.

(50) Chai, J.-D.; Head-Gordon, M. J. Chem. Phys. 2008, 128, 084106.

(51) Zhao, Y.; Truhlar, D. G. Theor. Chem. Account 2008, 120, 215-241.

(52) Frisch, M. J.; Trucks, G. W.; Schlegel, H. B.; Scuseria, G. E.; Robb, M. A.; Cheeseman, J. R.; Scalmani, G.; Barone, V.; Mennucci, B.; Petersson, G. A.; Nakatsuji, H.; Caricato, M.; Li, X.; Hratchian, H. P.; Izmaylov, A. F. et al. Gaussian 09 Revision A.1. Gaussian Inc. Wallingford CT 2009.

(53) Allouche, A. R. J. Comput. Chem. 2011, 32, 174-182.

(54) Andrae, D.; Haussermann, U.; Dolg, M.; Stoll, H.; Preuss, H. Theor. Chim. Acta 1990, 77, $123-141$.

(55) Weigend, F.; Ahlrichs, R. Phys. Chem. Chem. Phys. 2005, 7, 3297-3305.

(56) Tiago, M.; Idrobo, J.; Ogut, S.; Jellinek, J.; Chelikowsky, J. Phys. Rev. B 2009, 79, 155419.

(57) Pickering, J. C.; Zilio, V. Eur. Phys. J. D 2001, 13, 181-185.

(58) Beutel, V.; Kramer, H. G.; Bhale, G. L.; Kuhn, M.; Weyers, K.; Deltroder, W. J. chem. Phys. 1993, 98, 2699-2708.

(59) Antic-Jovanovic, A.; Kuzmanovic, M.; Khakoo, M. A.; Laher, R. R. Russian Journal of Physical Chemistry A 2011, 85, 2363-2367.

(60) Antic-Jovanovic, A.; Kuzmanovic, M.; Bojovic, V.; Khakoo, M. A.; Laher, R. R. J. Quant. Spectro. Radia. Transfer 2010, 111, 1357-1362.

(61) Laher, R. R.; Khakoo, M. A.; Kuzmanovic, M.; Bojovic, V.; Antic-Jovanovic, A. J. Quant. Spectro. Radia. Transfer 2011, 112, 786-792. 
(62) Antic-Jovanovic, A.; Momcilovic, M.; Bojovic, V.; Khakoo, M. A.; Laher, R. R. J. Serb. Chem. Soc. 2010, 75, 659-667.

(63) Laher, R. R.; Khakoo, M. A.; Antic-Jovanovic, A. J. Mol. Spectroscopy 2008, 248, 111-121.

(64) Fournier, R. J. Chem. Phys. 2001, 115, 2165-2177.

(65) Lee, H. M.; Ge, M.; Sahu, B. R.; Tarakeshwar, P.; Kim, K. S. J. Phys. Chem. B 2003, 107, 9994-10005.

(66) Fernandez, E. M.; Soler, J. M.; Garzon, I. L.; Balbas, L. C. Phys. Rev. B 2004, 70, 165403.

(67) kresin, V. V. Phys. Rev. B 1995, 51, 1844-1849.

(68) Serra, L.; Rubio, A. Phys. Rev. Lett. 1997, 78, 1428-1431. 


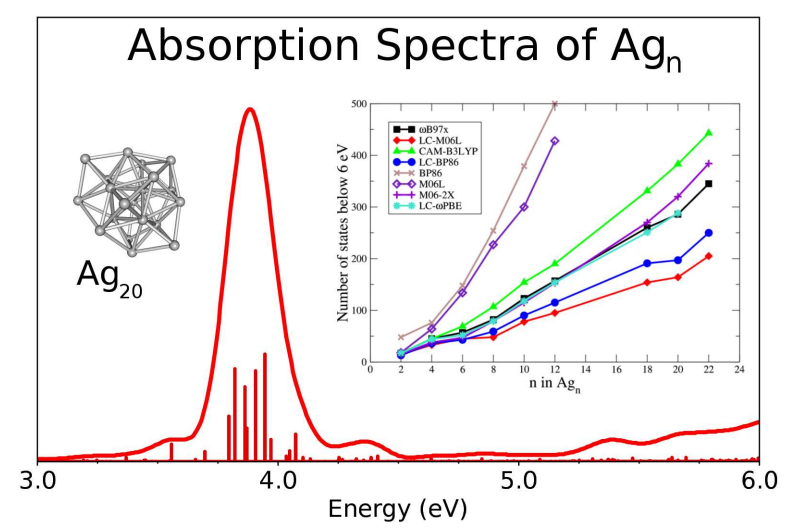

Figure 8: Table of Contents Graphic

This material is available free of charge via the Internet at http://pubs . acs . org/. 


\section{Assessment of the performance of long-range corrected density functionals for calculating the absorption spectra of silver clusters}

Franck Rabilloud*

Institut Lumière Matière, UMR5306 Université Lyon 1 - CNRS, Université de Lyon 69622 Villeurbanne Cedex, France

E-mail: franck.rabilloud@univ-lyon1.fr

${ }^{*}$ To whom correspondence should be addressed 


\section{Supporting Information Available}

Figures 1 and 2 show the absorption spectra of $\mathrm{Ag}_{6}$ and $\mathrm{Ag}_{8}$ using two different basis sets: SDD and QZVP. They show that spectra are similar with the two basis sets.

Figure 3 shows both calculated and experimental spectra of $\mathrm{Ag}_{2}$.

Table 1 gives the positions of main peaks. 

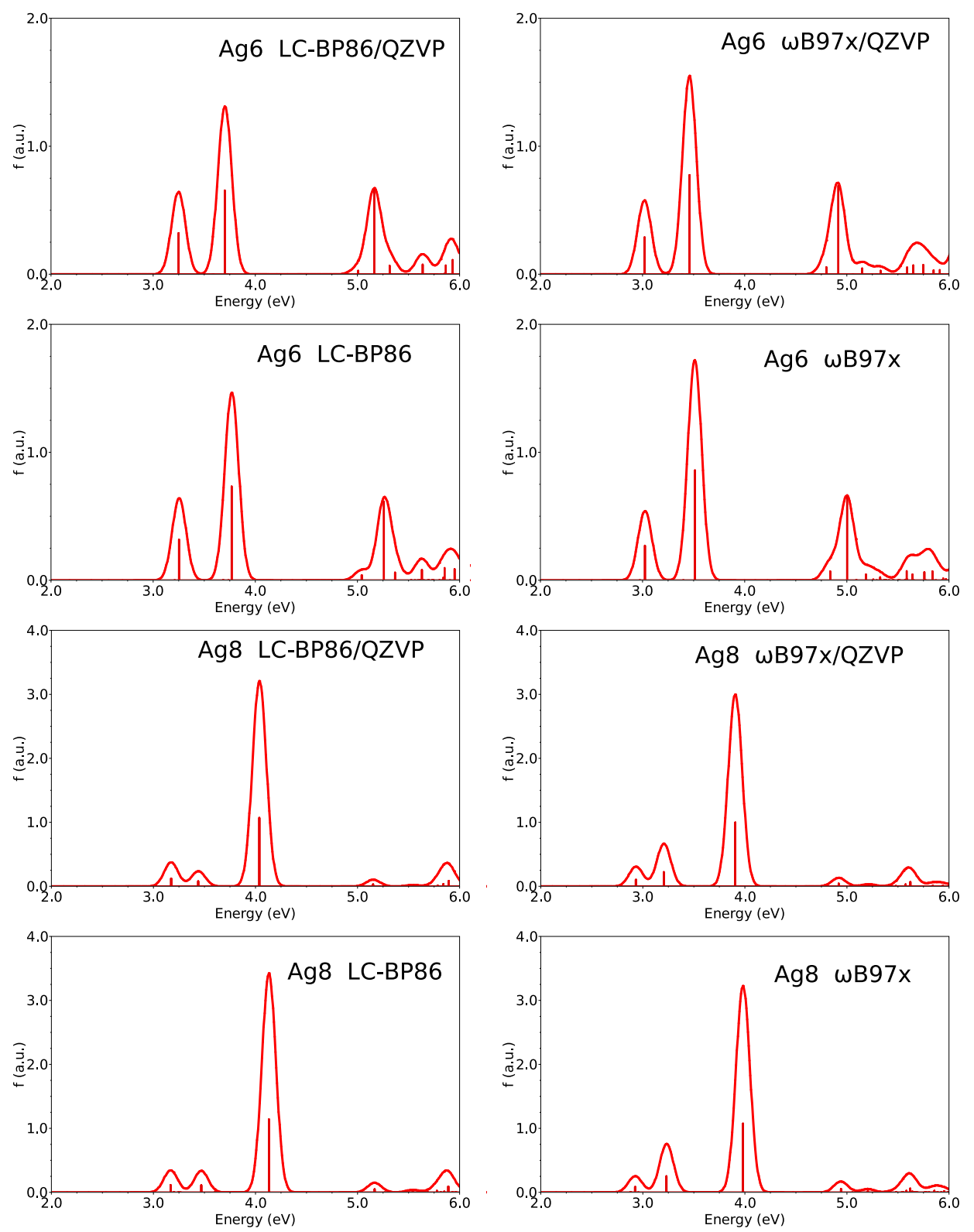

Figure 1: Absorption spectra of $\mathrm{Ag}_{6}$ ( $D_{3 h}$ symmetry) and $\mathrm{Ag}_{8}$ ( $T_{d}$ symmetry) clusters with LCBP86 and $\omega$ B97x functionals and using two basis sets: QZVP and SDD. 

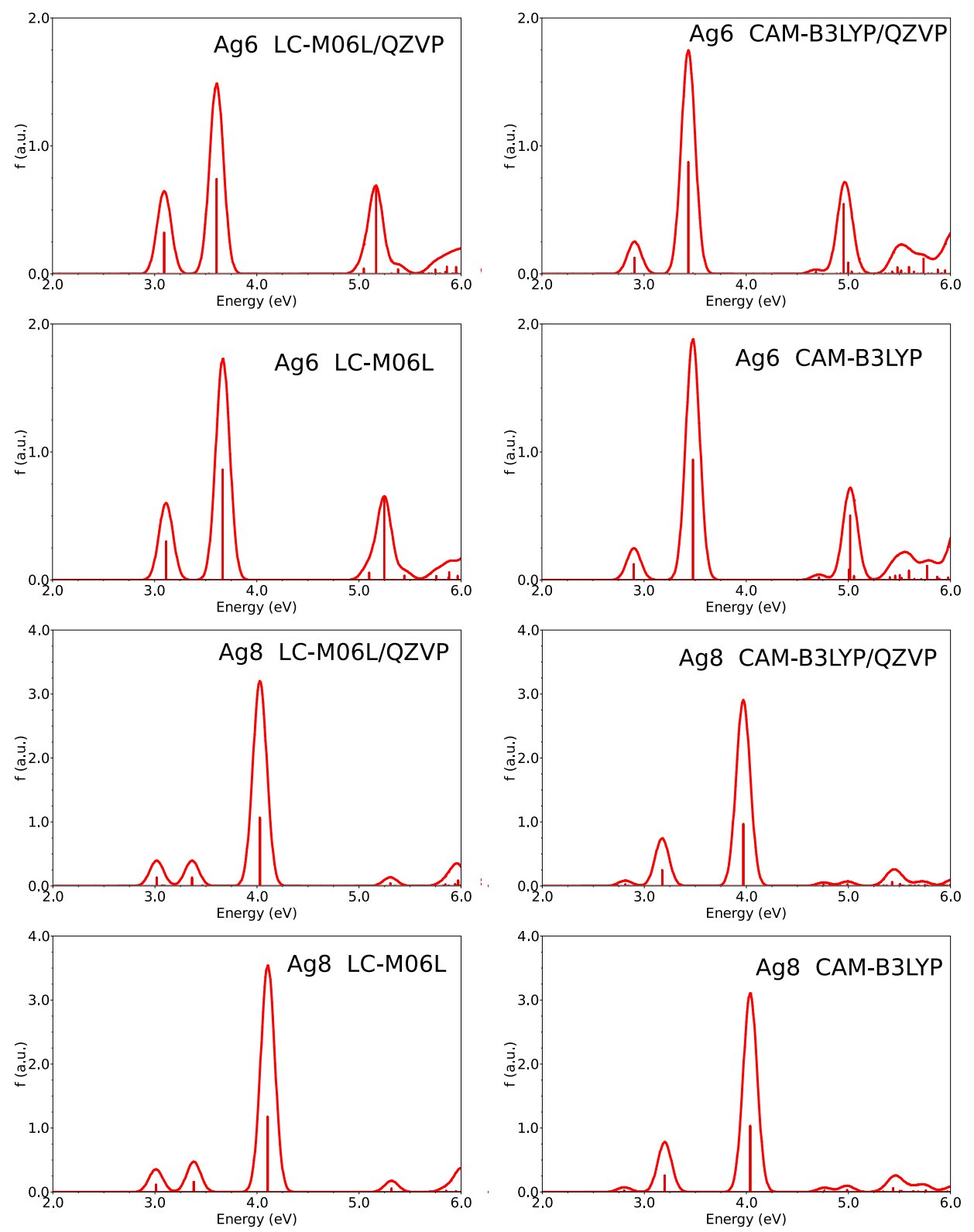

Figure 2: Absorption spectra of $\mathrm{Ag}_{6}\left(D_{3 h}\right.$ symmetry) and $\mathrm{Ag}_{8}\left(T_{d}\right.$ symmetry) clusters with LCM06L and CAM-B3LYP functionals and using two basis sets: QZVP and SDD. 

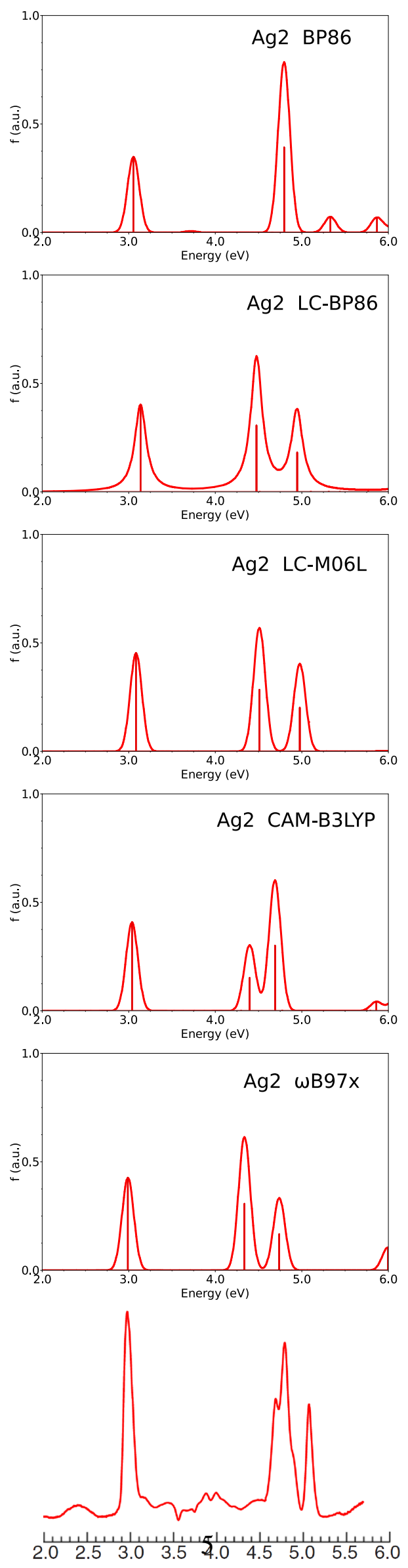

Figure 3: Absorption spectra of $\mathrm{Ag}_{2}$. Plots of the experimental spectrum (last row) was generated using digitizing software on the original spectra. ${ }^{1}$ 
Table 1: Main transitions of the absorption spectra of $\operatorname{Ag}_{n}(n=4,6,8,12,18,20)$ clusters. Experimental data are taken from References. ${ }^{1-3}$ EOM-CC values are taken form References. ${ }^{4,5}$

\begin{tabular}{llllllll}
\hline $\mathrm{n}$ & expt & BP86 & LC-BP86 & LC-M06L & CAM-B3LYP & wB97x & EOM-CC \\
\hline 4 & 3.07 & 2.95 & 3.18 & 3.12 & 3.05 & 2.98 & 3.21 \\
4 & 4.23 & 4.08 & 4.02 & 4.30 & 4.09 & 4.09 & 4.29 \\
6 & 3.45 & 3.23 & 3.77 & 3.67 & 3.48 & 3.51 & 3.69 \\
$8\left(T_{d}\right)$ & 4.00 & 3.82 & 4.13 & 4.11 & 4.04 & 3.98 & 4.16 \\
$8\left(D_{2 d}\right)$ & 3.65 & 3.33 & 3.88 & 3.83 & 3.72 & 3.69 & \\
$8\left(D_{2 d}\right)$ & 4.00 & 3.72 & 4.11 & 4.11 & 4.01 & 3.93 & \\
12 & 3.42 & 3.07 & 3.62 & 3.59 & 3.41 & 3.41 & \\
12 & 3.91 & 3.38 & 4.09 & 4.01 & 3.96 & 3.84 & \\
12 & 4.38 & 3.80 & 4.48 & 4.47 & 4.27 & 4.24 & \\
18 & 3.62 & 3.68 & 3.90 & 3.90 & 3.80 & 3.72 & \\
18 & 4.04 & & & & & & \\
20 & 3.70 & 3.33 & 4.09 & 4.09 & 3.88 & 3.91 & \\
20 & 3.97 & & & & & & \\
\hline
\end{tabular}

\section{References}

(1) Lecoultre, S.; Rydlo, A.; Buttet, J.; Felix, C.; Gilb, S.; Harbich, W. J. Chem. Phys. 2011, 134, 184504.

(2) Fedrigo, S.; Harbich, W.; Buttet, J. Phys. Rev. B 1993, 47, 10706.

(3) Harb, M.; Rabilloud, F.; Simon, D.; Rydlo, A.; Lecoultre, S.; Conus, F.; Rodrigues, V.; Felix, C. J. Chem. Phys. 2008, 129, 194108.

(4) Bonacic-Koutecky, V.; Pittner, J.; Boiron, M.; Fantucci, P. J. Chem. Phys. 1999, 110, 3876.

(5) Bonacic-Koutecky, V.; Veyret, V.; Mitric, R. J. Chem. Phys. 2001, 115, 10450.

This material is available free of charge via the Internet at http://pubs . acs.org/. 